\title{
Cardiac Resynchronization Therapy: State of the Art
}

Editors

LUIGI PADELETTI

MARTINA NESTI

GIUSEPPE BORIANI

\section{CARDIAC \\ ELECTROPHYSIOLOGY CLINICS}

www.cardiacEP.theclinics.com

Consulting Editors

RANJAN K. THAKUR

ANDREA NATALE

December 2015 • Volume 7 • Number 4 